Article

\title{
Assessing Incorrect Household Waste Sorting in a Medium-Sized Swedish City
}

\author{
Kamran Rousta ${ }^{1, *}$ and Karin M. Ekström ${ }^{2}$ \\ 1 School of Engineering, University of Borås, Allégatan 1, Borås 50190, Sweden \\ 2 School of Business and IT, University of Borås, Allégatan 1, Borås 50190, Sweden; \\ E-Mail: KarinM.Ekstrom@hb.se \\ * Author to whom correspondence should be addressed; E-Mail: Kamran.Rousta@hb.se; \\ Tel.: +46-33-435-46-44; Fax: +46-33-435-40-08.
}

Received: 24 June 2013; in revised form: 25 September 2013 / Accepted: 26 September 2013 / Published: 2 October 2013

\begin{abstract}
Source separation is a common method for dealing with the increasing problem of Municipal Solid Waste (MSW) in society. The citizens are then responsible for separating waste fractions produced in their home. If the consumers fail to sort the waste according to the source separation scheme, it will lead to an ineffective system. The purpose of this paper is to analyze the environmental, economic and social aspects of incorrect waste sorting in a medium sized Swedish city that has established a source separation system. In order to determine the extent to which citizens correctly sort their waste, food waste (black bags) and combustible fraction (white bags), were collected randomly from a residential area and categorized in different waste fractions. The results show that approximately $68 \mathrm{wt} \%$ of the waste in the white and $29 \mathrm{wt} \%$ in the black bags were not sorted correctly. This incorrect sorting accrues over 13 million SEK per year cost for this community. In order to improve the inhabitants' participation in the waste management system, it is necessary to change different factors such as convenience and easy access to the recycling stations in the local MSW management systems as well as to review current regulation and policy.
\end{abstract}

Keywords: solid waste management; source separation; Sweden; recycling behavior 


\section{Introduction}

Problems with household waste have increased over time, in parallel to the development of consumer society. As consumption increases, waste is generally also increasing in quantity and variety. This means depletion of the resources and consequently, environmental problems such as global warming if there is no sustainable way to manage this issue. These environmental problems have significant social and economic impacts [1]. For instance, if waste is just dumped into the land, i.e., landfilling, it causes pollutions in the air, water and soil as well as health hazards [2]. Besides the environmental impacts and high cost of operating the landfill, establishing a new landfill is not an easy task [3]. That is why the European Union (EU) has developed a waste strategy that advocates the Thematic Strategy on the Prevention and Recycling of Waste [4]. According to this strategy, a waste management hierarchy has been formed [5]. This implies that waste should first of all be prevented, then reused and thirdly, recycled. If there is no way to apply the first three steps, waste should be used as a source of energy. Finally, in the event that the last four steps do not result in any solution, waste should be dumped in a controlled landfill. Sweden is one of the foremost EU countries in applying the waste management hierarchy. During 2011, 4.3 million tons municipal solid waste were generated from households in Sweden, which implies about $460 \mathrm{~kg}$ per person per year [6]. Fifty-one per cent of the household waste generated was used for energy recovery, 33\% for recycling, $15 \%$ for biological treatment, and less than one per cent to landfill [6]. In 2011, material recycling increased about five times more than the amount in 1975 [6]. Apart from the different regulation and technological development, sorting the waste at the source by citizens is the key for this success. Sorting waste decreases the solid waste management cost and improves the efficiency of recycling and the quality of recovered material [3]. A higher rate of source separation will increase the rate of recycling, which will then result in efficient and economical treatments for waste incineration and biogas production as well as reduction in environmental impacts as a result of the waste $[7,8]$. However, to succeed in separation of household waste, inhabitants have to manage and separate waste in their homes where it is generated. It is, therefore, important to have a consumer perspective when developing such a system. A consumer perspective requires an understanding of the consumers' residential area in order to make it easier for them to sort and separate waste there. Also, uncertainty about which material is packaging or non-packaging, recyclable or non-recyclable, increases the probability of incorrect sorting of waste from a consumer's perspective [9]. It is also not efficient if the consumer has to travel long distances to bring her/his waste to a recycling station. The system should therefore be as simple and user-friendly as possible in order to motivate the consumers to be participants [10].

In order to understand the imperative role of the citizens in the Municipal Solid Waste (MSW), a case is presented in this paper namely the municipality of Borås with a population around 105,000 [11], located in the southwest of Sweden. Since 1991, inhabitants in Borås have been requested to sort their waste at home and as a result less than $0.4 \%$ of the total households' waste generation was dumped in the landfill in 2009 [12]. The residents sort the food waste and combustible waste in black and white bags, respectively. Thereafter, this waste is transferred to Material Recovery Transformation Facilities (MR/TF). Food waste in black bags is converted into biogas to fuel cars and public transportation, and the combustible parts in white bags are prepared as Refuse Derived Fuel (RDF) for power plants to produce heat and electricity. Since 1994 when the Ordinance on Producer Responsibility [13,14] was 
introduced in Sweden, the recyclable material such as newspaper, plastic-, paper-, metal- and glass packaging must all be separated by the citizens and transferred to recycling stations. Based on this law, Packaging and Newspaper Collection (FTI) is the service organization that is responsible for managing the collection and recycling the packaging. This organization is financed by packaging fees and the selling of the collected material [15]. For glass packaging, "SvenskGlas Atervinning" is the company which collects and recycles the glass packaging [16]. According to statistics from FTI, 92\% glass, 74\% paper packaging, 68\% metal, 26\% plastic packaging and 92\% newspaper (in 2009) were recycled from Swedish households waste in 2011[17].

Based on the different sorting activities in the Municipal Solid Waste Management (MSWM) system of Borås, Figure 1 illustrates the three streams of household waste, which are collected and transferred to different places in this system.

Figure 1. Different streams of waste collection in Borås [18].

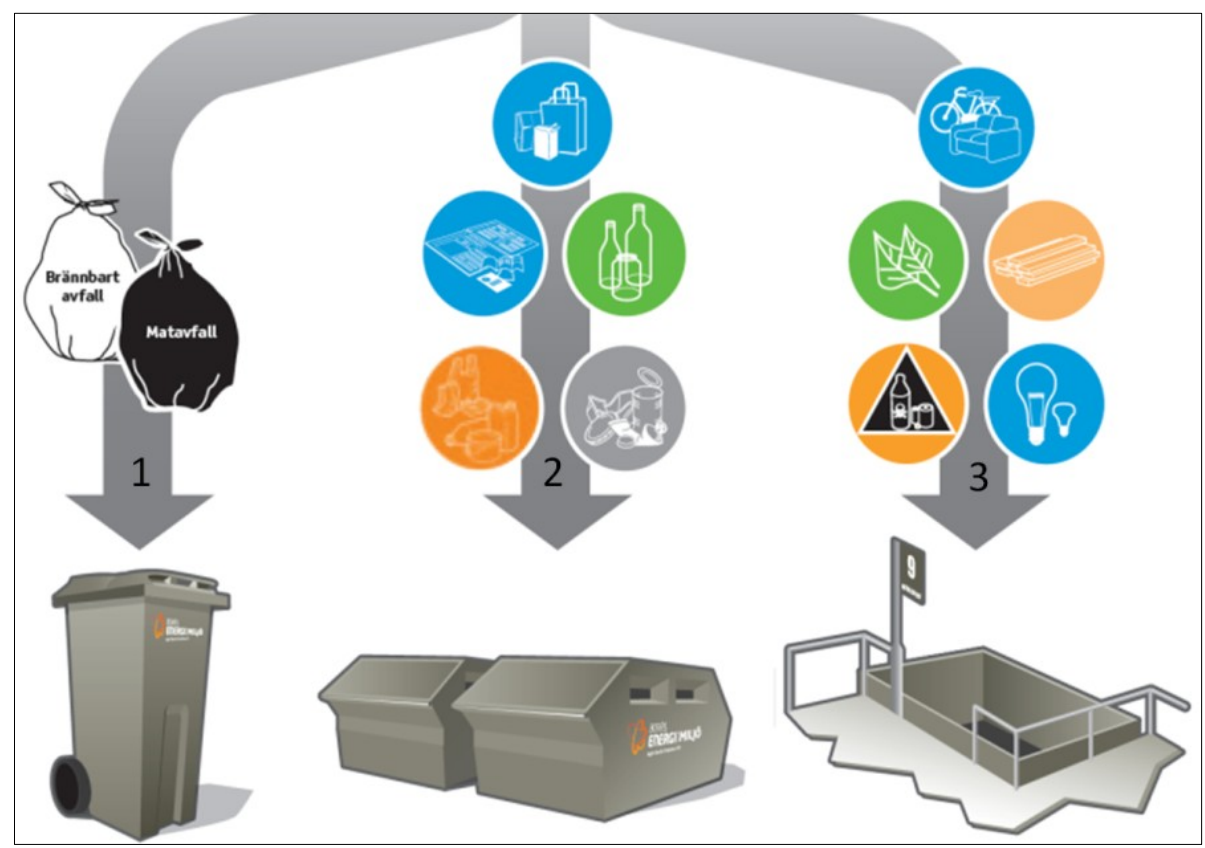

Flow 1: Inhabitants sort the food waste in black bags and the combustible waste in white bags, which are then collected and transferred to MR/TF for further processing by "Borås Energi och Miljö" (BEM), the municipality company in Borås.

Flow 2: The packaging material needs to be sorted by inhabitants and collected at recycling stations. FTI and "SvenskGlasÅtervinning" are responsible for managing the collection and recycling this type of waste.

Flow 3: The other type of waste, such as bulky waste like furniture, white goods such as refrigerators and garden waste, hazardous waste, electronic waste, etc. needs to be transferred to recycling centers by inhabitants. BEM is responsible for these centers. All the collected waste in these centers is then transferred to industries for further processes. For instance, SAKAB is one of the biggest companies in Sweden that takes care of the hazardous waste. They take out the toxic substances from the hazardous waste and then treat them thermally to produce heat and electricity [19]. 
As indicated above, the Borås model for waste management relies heavily on the separation of the waste at the source. The efficiency of the different processes in this system is based on the quality of the material, i.e., the separated waste, which feed into the system. For instance, for better biogas production, it is necessary that the black bags include only the food waste and not any other material. Also, if the packaging materials instead of being transferred to the recycling stations are sorted incorrectly in the white bags, they will be burned rather than recycled which is not an optimal solution. Since the model relies on separation at the source, the participation of the citizens in the source separation scheme is crucial in order for the system to succeed.

The Municipal Solid Waste Management (MSWM) is a complicated and sophisticated system since it involves environmental, economic, and social aspects and their effects on each other [20]. It is necessary to consider environmental aspects in order to reduce environmental damage. Furthermore, a system that is not economically justifiable will not be successful in the long run. Moreover, a system for waste management will not work if it is not accepted and used by the citizens; therefore, the social aspects are imperative. Even though there are some studies comparing features of different scenarios in waste management processes such as landfilling, incineration and recycling from environmental and economic point of view [7,21-23], there is still a need to consider the social aspects in solid waste management. There are also studies that compare the different scenarios in collection systems and the role of the source separation scheme in these scenarios [24-26]. However, there has been no specific study that quantifies the role of consumers in the waste source separation scheme. In a MSWM based on separation at the source, like in the Borås model, it is crucial that the inhabitants sort the fractions correctly. It is therefore of interest to determine how important it is that the citizens do a correct job in a source separation scheme. This paper is the first part of a larger study on the social aspects in waste management, analyzing the inhabitants' participation in waste separation at the source as well as the interaction of the social aspects with the other aspects in waste management. This paper specifically examines waste sorting in the municipality of Borås. The purpose of the paper is to show the effect of separation at the source in the waste management system by quantifying the role of the inhabitants in such a system. This paper assesses the community cost when the waste is not sorted correctly in a source separation scheme. Based on the results, suggestions are made on how to improve the system.

\section{Materials and Methods}

The study was conducted in the western part of Borås in a residential area that is called the "pilot area" in this paper. The pilot area includes 447 inhabitants who live in 208 apartments in nine apartment blocks where each has eight floors. The tenants are renters and represent a variety of nationalities with different socio-economic backgrounds. According to Swedish Statistics, about 33\% of the residents in this area are native and the rest are immigrants [27]. About $63 \%$ of the residents are low income households and about $42 \%$ have no upper secondary education [27]. The majority of the inhabitants have lived in this area for more than five years [27]. The closest recycling station (flow 2 in Figure 1) is located at the back of the apartment blocks, where there are containers for newspapers and glass packaging only. The closest recycling center (flow 3 in Figure 1) is located 2 kilometers from this residential area. 
A pick analysis was applied in the pilot area in order to identify the total waste generation and waste characterization. In addition, the results of the pick analysis can present qualitative information about the available waste management system [28]. The pick analysis was conducted based on instructions from "Avfall Sverige" (The Swedish Waste Management Association) [29]. These instructions are common practice for pick analysis conducted in Sweden. It was done in November 2011, as there are no special holidays and national days in this month affecting the results. Therefore, the results of the pick analysis are representative of waste generation in this pilot area, in general. As the waste for the pilot area is collected once a week, wheeled bins were selected randomly over a four-week period, based on the Independent Random Sample (IRS), in order to get a more random result that did not vary according to a specific time. The random bins were transferred to a specific place that had necessary instruments to measure the different fractions of the waste. The measurements were conducted by one of the authors and two assistants. Because of the health and safety concerns, special clothes, masks and suitable gloves were worn. Weight measurement of the waste fractions in the white and black bags was conducted by using an electronic wave balance (Tanita, max. $50 \mathrm{~kg}$ ) with a measurement accuracy of $0.05 \mathrm{~kg}$. The waste was categorized into: food, combustible (such as envelope, paper towels, diapers), packaging, hazardous (such as glue, painting materials, batteries and lights) and other. For further investigation, the packaging was sorted into four categories of packaging: plastic, paper, metal and glass and one category for newspaper. The total waste samples weight was $1732.8 \mathrm{~kg}$, which amounted to $28 \%$ of the waste generation for this area in four weeks. The total selected samples from this pilot area included twenty-eight bins. The total selected samples included 1332 white bags with a weight of $1070.7 \mathrm{~kg}$ and 675 black bags with a weight of $662.1 \mathrm{~kg}$. First, each bin was weighed and then the white and black bags were weighed separately. All the waste fractions mentioned above were weighed and documented. The process of sorting and measurement was also documented by memos and by taking photographs. After completing the measurement, a statistical analysis was conducted with data analyzed by MINITAB, and the mean value (in per cent) of five categories of waste in white and black bags, respectively, was determined. The data were used to identify the ratio of incorrect sorting, estimation of the characterization of waste generation and the calculated cost for incorrect waste sorting for this pilot area.

For some of the assessments, information from the MSWM in Borås as well as some information from the companies who are involved in collecting the packaging material was needed. Therefore, a structural interview was conducted as well as e-mail communications with a business developer who works in the municipality company, "Borås Energi och Miljö" (BEM), which is responsible for waste management in Borås. Furthermore, phone enquiries were conducted with the CEO of "Pressretur" (company responsible for newspaper recycling) as well as a person responsible for the statistics at "SvenskGlasÅtervinning" (a company that collects and recycles the glass packaging in Sweden). The main reason for interviews was to gather facts about the cost of different processes as well as more information for clarifying the processes.

\section{Results}

In this section, the results are illustrated and the ratio of incorrect sorting, the characterization of the waste and the cost for incorrect waste sorting for the pilot area are determined. 


\subsection{Ratio of Incorrect Sorting}

The results of the statistical analysis of the measurement as well as the mean value of the proportion of the five categories are shown in Figures 2 and 3 for white and black bags, respectively, with a 95\% confidence interval. The results presented in Figure 2 show that about $32 \mathrm{wt} \%$ of the waste in the white bags (combustible) was sorted correctly. The majority of the faulty sorting in these bags consisted of packaging materials, around $43 \mathrm{wt} \%$, which should have been sorted at recycling stations. About $22 \mathrm{wt} \%$ of the waste in the white bags was food waste, which should have been sorted in black bags.

Figure 2. Proportion of different waste categories in white bags intended for combustible waste.

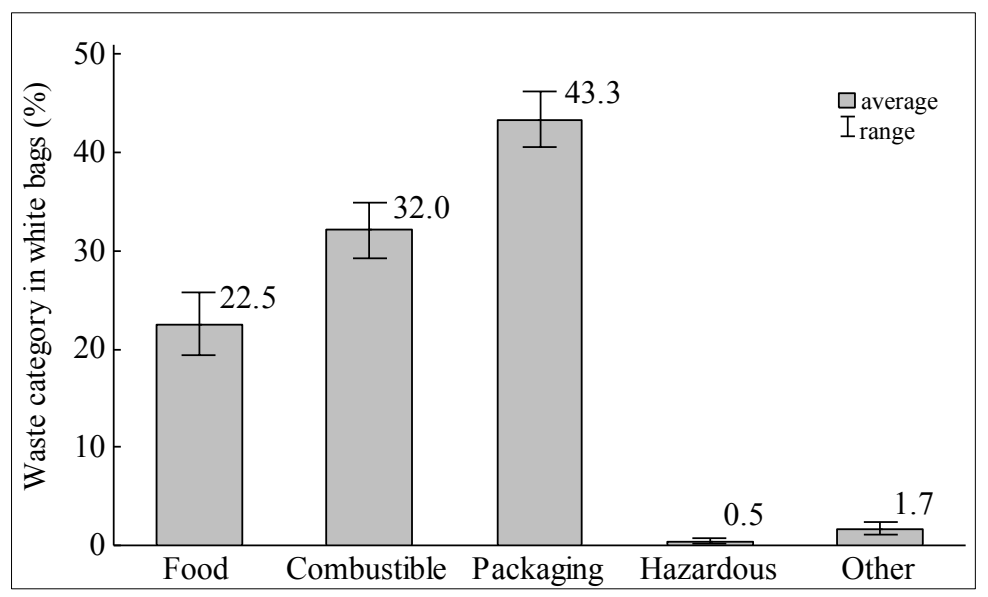

The results presented in Figure 3 show that about $71 \mathrm{wt} \%$ of the black bags was food waste that was sorted correctly. Also, the black bags included approximately $18 \mathrm{wt} \%$ combustible material and $10 \mathrm{wt} \%$ packaging that were sorted incorrectly. Although the amount of hazardous waste in both white and black bags that should have been transferred to recycling centers was less than $0.5 \mathrm{wt} \%$ of total waste generation, this little amount needs to be reduced because of health hazards. In summary, $68 \mathrm{wt} \%$ of the waste in white and $29 \mathrm{wt} \%$ in black bags were not sorted correctly. According to the results, the ratio of incorrect sorting in this area was determined to be $53 \mathrm{wt} \%$. In other words, $53 \mathrm{wt} \%$ of the total waste in this area had not been sorted correctly.

Figure 3. Proportion of different waste categories in black bags intended for food waste.

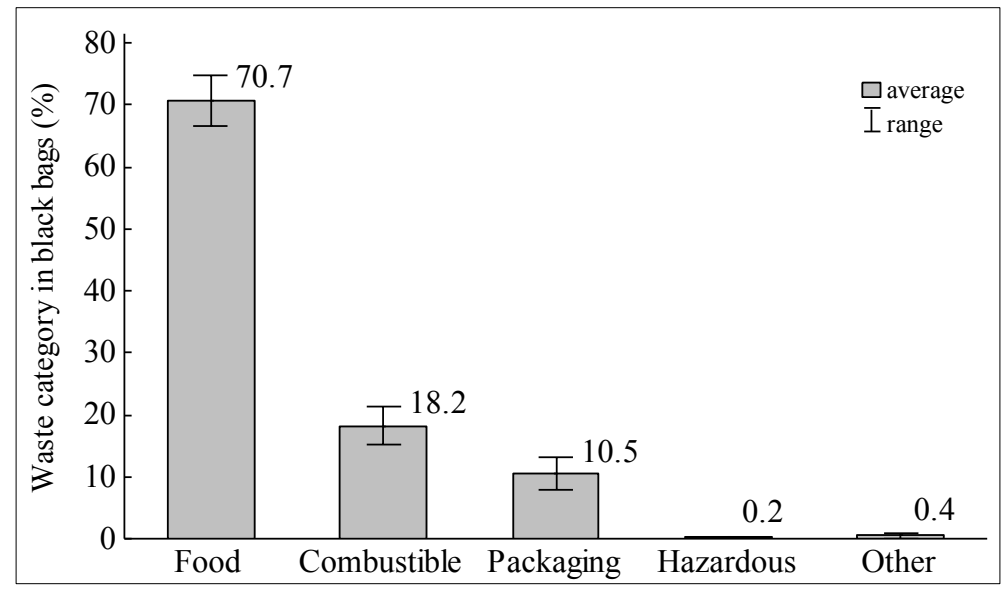




\subsection{Waste Characterization}

The statistical analysis by ANOVA (Analysis of Variance) shows that the difference between the four weeks sampling periods is not significant. This means that there is no difference in waste characterization between the weeks in this pilot area. Thus, based on the results of the pick analysis, the estimated average amount of different fractions of waste in white and black bags per household per year in this residential area is presented in Table 1. As illustrated in this table, in this pilot area, on average $53.8 \mathrm{~kg}$ food waste, $38.3 \mathrm{~kg}$ newspaper, $26.5 \mathrm{~kg}$ paper packaging and $23.7 \mathrm{~kg}$ plastic packaging are the fractions that were sorted most incorrectly in the white bags by each household per year. In the black bags, the fractions that were sorted most incorrectly are combustible waste with $26.9 \mathrm{~kg} /$ household/year. It can also be calculated that the total waste generation of each household is about $386.7 \mathrm{~kg} /$ year which corresponds to an average of $7.4 \mathrm{~kg}$ of waste generation per week per household in this residential area.

Table 1. The content of white bags intended for combustible waste and black bags intended for food waste in $\mathrm{kg} /$ household/year for the pilot area with 447 inhabitants.

\begin{tabular}{lcc}
\hline Type of the waste & White bags & Black bags \\
\hline Plastic packaging & 23.7 & 5.4 \\
Paper packaging & 26.5 & 3.6 \\
Metal packaging & 5.3 & 1.6 \\
Glass packaging & 9.7 & 2.5 \\
Newspaper & 38.3 & 2.4 \\
Food waste & 53.8 & 104.5 \\
Combustible & 76.5 & 26.9 \\
Hazardous & 1.2 & 0.3 \\
Other & 4.1 & 0.6 \\
Total & $\mathbf{2 3 8 . 9}$ & $\mathbf{1 4 7 . 8}$ \\
\hline
\end{tabular}

\subsection{Cost Calculation}

If all the waste is sorted as shown in Figure 1, it can be an ideal scenario for waste sorting in Borås. This means that all the food waste is sorted in black bags, combustible waste in white bags, all the packaging is sorted at recycling stations and hazardous waste and other types of waste are transferred to the recycling centers. As a result, the waste tariff paid by the inhabitants to the municipality would be appropriately used. Also, FTI, which is partly financed by producers through packaging fees, would collect all the packaging material. If this were the case, there would be no extra cost for the community. Here, the community is defined as all the people who are living in the city and pay taxes and different tariffs to finance their social services including the waste management system. In this case, the community cost means that the taxes and tariffs which are paid by the community are not used in the appropriate way and therefore causes a waste of resources. For instance, recyclable fractions of waste are burnt even though a waste tariff has been paid by the community for recycling. This means that the resources which are provided by the community are not used in the right way; this is the definition of the community cost in this paper. 
According to this definition, the possible costs that are imposed on the community, based on the incorrect waste sorting in terms of countable and uncountable costs are shown in Figure 4.

Figure 4. The countable and uncountable cost of the incorrect waste sorting for Borås community.

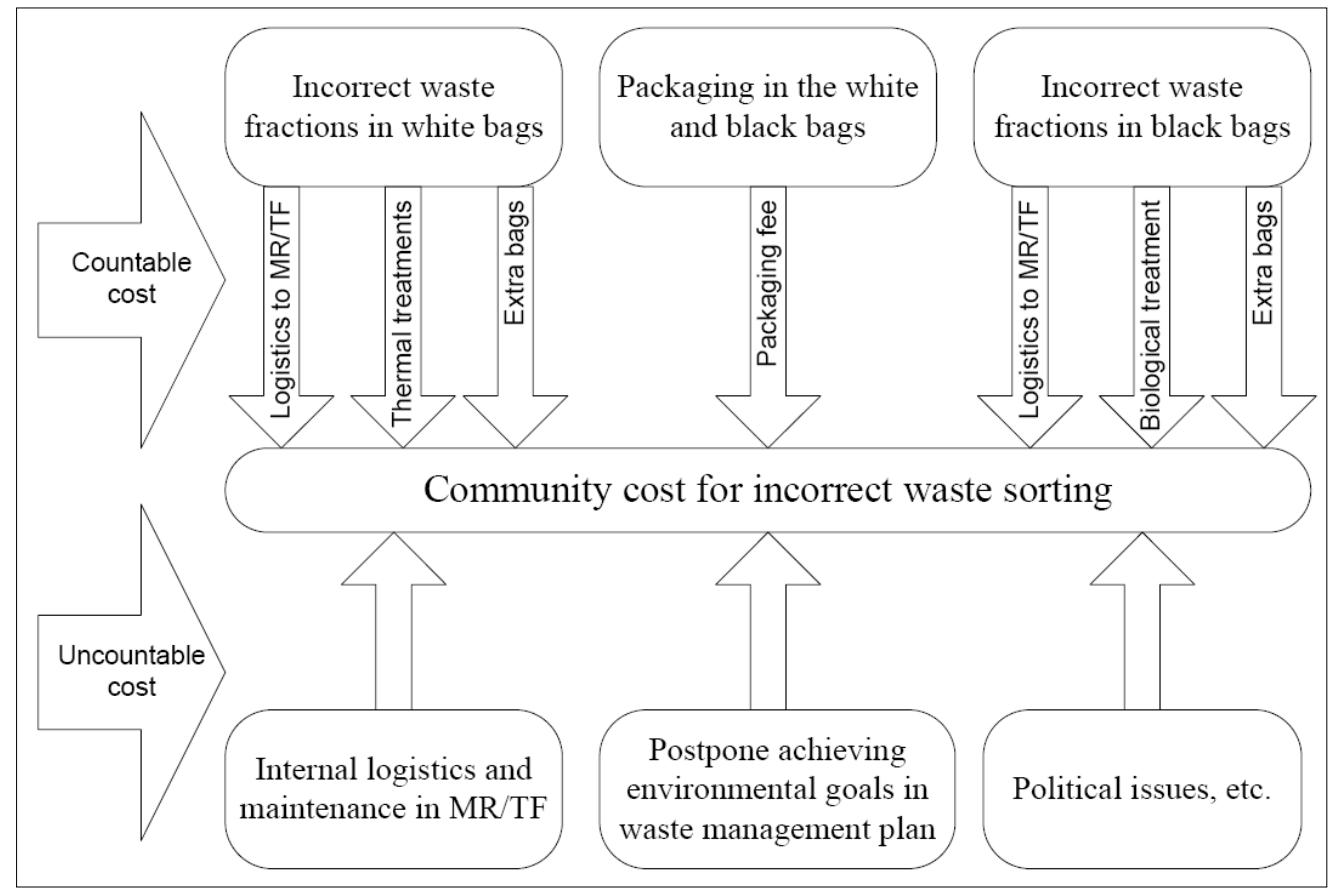

The countable cost means the ones that are possible to count in currency. The reason for these costs is the fact that the fractions are not sorted correctly in white and black bags. Some of these costs are the logistics cost from household to MR/TF $(1.11 \mathrm{SEK} / \mathrm{kg})$, thermal treatment $(0.45 \mathrm{SEK} / \mathrm{kg})$ and biological treatment $(0.62 \mathrm{SEK} / \mathrm{kg})$ that is covered by the BEM company [30]. For example, when a metal packaging gets into black bags instead of being sorted at recycling stations, it will transfer to $\mathrm{MR} / \mathrm{TF}$ instead of being collected by FTI, this is identified by "logistics to MR/TF" in Figure 4. Also, when it is in the black bags, it is processed in a biological treatment, but it is not possible to produce biogas from a metal packaging. This means that the tariff which should finance the biological treatment for the food waste is used wrongly for the fractions which are sorted incorrectly. In Figure 4, this is shown as the "biological treatment" arrow.

Also, the white and black bags that are used by the households to separate the combustible and food waste are distributed to the inhabitants free of charge. Incorrect sorting of the waste materials in these bags therefore contribute to the usage of more bags [30]. The parts that are not sorted correctly occupy the main volume of the white and black bags. This was also found in the observations during the pick analysis. Therefore, too many bags are used compared to if the households had sorted correctly. This results in an extra cost, which can be estimated to about 17,810 SEK/year in this pilot area (Table 2).

The other cost is the packaging fees for the part of the packaging that is sorted incorrectly in white and black bags. As mentioned before, the packaging fee is the one that producers and importers pay to FTI and to the glass recycling company in advance, in order to collect and recycle these materials. In practice, the packaging fee is included the price of the goods that the consumers pay. The packaging fee is therefore paid by the community and if it is not used appropriately, it will be counted as a 
community cost. When the waste is not sorted correctly, the packaging waste will not be collected by FTI; instead they are collected in white and black bags by BEM. This means that FTI is paid by the packaging fee more than the amount that they actually collect when the waste is not sorted correctly. However, FTI is not the cause of this cost. It is households' incorrect waste sorting that causes the cost. This cost is identified by the "packaging fee" arrow in Figure 4.

For newspapers, this cost is not specific because the paper industries cover the recycling costs. When they in turn sell the raw paper, they include this cost [31,32]. However, other kinds of packaging have fixed fees. Packaging such as plastic (1.71 SEK/kg), paper (1.08 SEK/kg) and metal (steel 2.84 $\mathrm{SEK} / \mathrm{kg}$ and aluminium $2.32 \mathrm{SEK} / \mathrm{kg}$ ) are the responsibility of FTI [33]. The fee for glass packaging is about $0.60 \mathrm{SEK} / \mathrm{kg}$, which "SvenskGlasÅtervinning" is responsible for collecting and recycling [34]. The producers and importers have already paid for all the packaging materials to FTI with the packaging fees based on the above-mentioned fees. The total amount for the packaging fee calculated in Table 2 is about 26,000 SEK/year in this pilot area which is around $28 \%$ of the total calculated cost. This means that if these materials were sorted at the recycling stations, FTI would use this money to collect them. However, when they were incorrectly sorted in white and black bags, they were not available to be collected by FTI. Therefore, in this case, FTI has been paid even though they did not collect the packaging materials. Therefore, it is counted as a cost for the community. All the fractions that are not sorted correctly in both white and black bags incur a logistics cost, which is estimated to about 28,860 SEK/year. The incorrectly sorted materials in black bags require biological treatment costs (5,590 SEK/year), and the incorrectly sorted materials in the white bags require thermal treatment costs $(15,210 \mathrm{SEK} /$ year $)$. Based on these assessments, the total countable costs for this area are calculated to be 93,470 SEK/year (Table 2). Also, the cost for incorrect waste sorting can be estimated to about 1.1 SEK per $\mathrm{kg}$ waste generation for this residential area. This was calculated by dividing the yearly cost $(93,470$ SEK) by total waste generation collected in white and black bags in a year.

Table 2. The countable costs of incorrect waste sorting for the pilot area with 447 inhabitants.

\begin{tabular}{lcc}
\hline \multicolumn{1}{c}{ Cost } & SEK/year & EUR/year \\
\hline Logistics & 28,860 & 3,255 \\
Packaging fee & 26,000 & 2,933 \\
Cost for extra bags & 17,810 & 2,009 \\
Preparation for RDF and thermal treatment & 15,210 & 1,715 \\
Biological treatment & 5,590 & 631 \\
Total & $\mathbf{9 3 , 4 7 0}$ & $\mathbf{1 0 , 5 4 3}$ \\
\hline
\end{tabular}

In order to estimate this cost for the city of Borås, the results of a pick analysis that had been conducted by BEM in 2010 were analyzed. This pick analysis was from three residential areas in Borås representing a variety of socio-economic background as well as apartments and houses [30]. The results of this pick analysis show that the incorrect sorting ratio was about $42 \mathrm{wt} \%$, which can be considered a value for the Borås city. By considering the average figures and waste characterization of the pilot study, and generalizing the calculated cost of this area to the Borås municipality, with about 105,000 inhabitants, an estimated cost for incorrect sorting in Borås would be over 13 million SEK (1.46 million EUR) that is imposed on the Borås community yearly. 
As it is illustrated in Figure 4, there are some other costs for the incorrect sorting that remain uncountable. For example, the incorrect materials in black bags, which are not biodegradable and that are used for the biogas process also causes high maintenance cost if the machines malfunction [30]. The internal logistics cost related to transfer of the huge amount of the incorrect materials in MR/TF is yet another cost, which is not possible to calculate because there is no specific data in the system to determine it [30]. Also, decisions about the policy and regulation in waste management are usually made as part of a political process that consumes time and resources. However, when a system does not work properly, this process still imposes a cost on the society. If the waste is not sorted correctly, these above-mentioned uncountable costs are still costs for the community.

\section{Discussion}

According to the results, the community cost for the city of Borås would be 13 million SEK for incorrect sorting per year. This is a significant amount of money, which can be used in more effective and better ways for the city. To get a perspective on how much money this is, it is important to note that the identified budget for information and education of the inhabitants on how to sort the waste is about 350,000 SEK/year [30] which is less than 3\% of the calculated cost for the incorrect sorting. This means that it is worthwhile for Borås to re-think the existing MSWM system in order to make it more convenient and understandable for the inhabitants to participate in source separation. Even though sorting all the waste fractions correctly may not be possible to achieve, it needs to be acknowledged that a reduction of the incorrect sorting ratio saves the community's resources.

Included in this cost is the cost for the packaging fee, which is about $28 \%$ of the total cost. Although the reason for this cost is incorrect sorting by the inhabitants, there is a need to review the policy and regulation in this field in order to achieve a more effective cooperation between FTI and the municipalities. In Borås, from the residents' perspective, BEM is responsible for the entire waste management system, but the collecting and recycling of the packaging are the responsibility for FTI. This raises the question regarding who is responsible for encouraging the residents to sort the waste correctly. Even though both actors are putting a lot of efforts into this, the result of this study shows that more effective and result-oriented actions are required in order to inform, educate and encourage the inhabitants to participate in the source separation schemes.

Besides economic aspects, the incorrect sorting shown in this study is a hindrance for the MSWM in Borås to move towards its sustainable strategy. The MSWM in Borås is based on the waste hierarchy top down; prevention, reuse, recycling, energy recovery, and landfilling. In the new waste management plan for 2020, it is stated that the main goal is to go towards the top of the waste hierarchy [12]; in other words, to prevent waste, reuse and recycling. In order to achieve this, the inhabitants have to participate more actively in the waste separation schemes and to sort the waste correctly. As it is now, the incorrectly sorted materials in white and black bags are transferred to power plants as fuel to produce electricity and heat in an energy recovery process; however, this is not a sustainable alternative. As mentioned above, based on the waste hierarchy, energy recovery is ranked lower compared to recycling. Therefore, this incorrect sorting actually prevents the achievement of the environmental goals which are stated in the waste management plan in Borås for 2020. 


\section{Conclusions}

Although waste separation at the source is known to be an effective method for sustainable waste management, it is based on the assumption that the inhabitants sort the waste correctly. The results in this study show that incorrect waste sorting can impose a significant cost on society. This cost for a medium-sized Swedish city like Borås, can be estimated to about 13 million SEK yearly. Therefore, it is necessary to investigate how to improve the available systems in order to make it more convenient for the consumers to participate in sorting the waste correctly. One way to do this could be to place recycling stations closer to the residential area (property-close collection system). Furthermore, it is not sufficient to merely inform, but necessary to educate people about the societal benefits of correct waste sorting. In order to do this, different communication campaigns needs to be developed targeting different groups of consumers. These result-oriented efforts require effective cooperation between actors such as the municipality and FTI, involved in the MSWM. This requires also a review of current regulation and policy in this field. Besides this, further research needs to study consumer behavior and to investigate different factors which can influence inhabitants' behavior in separation at the source and reducing the amount of waste. If the amount of waste is reduced, there will be less waste for the community to handle and these community costs will be saved.

\section{Acknowledgments}

The authors wish to acknowledge "Borås Energi and Miljö" for supporting and "Sjuhärads Kommunalförbund" for funding of this project.

\section{Conflicts of Interest}

The authors declare no conflict of interest.

\section{References}

1. Barr, S. Household Waste in Social Perspective; Ashgate: Aldershot, UK, 2002.

2. El-Fadel, M.; Findikakis, A.N.; Leckie, J.O. Environmental impacts of solid waste landfilling. J. Environ. Manage. 1997, 50, 1-25.

3. Tchobanoglous, G.; Theisen, H.; Vigil, S.A. Integrated Solid Waste Management: Engineering Principles and Management Issues; McGraw-Hill: New York, NY, USA, 1993; pp. 3-538.

4. EU. On the Thematic Strategy on the Prevention and Recycling of Waste. In Proceedings of the Report from the Commission to the European Parliament, The Council, The European Economic and Social Committee and the Committee of the Regions, Brussels, Belgium, 19 January 2011.

5. EU. On Waste and Repealing Certain Directives. In Proceedings of the Directive 2008/98/EC of the European Parliament and of the Council, Brussels, Belgium, 19 November 2008.

6. Swedish Waste Management. Statistics of Households' Waste (Hushållsavfall i Siffror) (in Swedish); Rapport U2012:18; Swedish Waste Management: Malmö, Sweden, 2012.

7. Bernstad, A.; la Cour Jansen, J.; Aspegren, H. Life cycle assessment of a household solid waste source separation programme: A Swedish case study. Waste Manag. Res. 2011, 29, 1027-1042. 
8. Eriksson, O.; Carlsson Reich, M.; Frostell, B.; Björklund, A.; Assefa, G.; Sundqvist, J.O.; Granath, J.; Baky, A.; Thyselius, L. Municipal solid waste management from a systems perspective. J. Clean. Prod. 2005, 13, 241-252.

9. Henriksson, G.; Åkesson, L.; Ewert, S. Uncertainty regarding waste handling in everyday life. Sustainability 2010, 2, 2799-2813.

10. Ewert, S.; Greger, H.; Åkesson, L. Osäker eller Nöjd: Kulturella Aspekter på Vardagens Avfallspraktik (in Swedish); KTH Royal Institute of Technology: Stockholm, Sweden, 2008.

11. Borås statistic. Available online: http://www.boras.se/forvaltningar/stadskansliet/stadskansliet/ samhallsplanering/samhallsplanering/borasisiffror/statistik.4.82f0a312665003f0d800014558.html (accessed on 24 June 2013).

12. Borås Energi och Miljö. Borås Waste Management Plan 2012-2020; Borås Energi och Miljö: Borås, Sweden, 2011.

13. SFS1994a, Förordningen om producentansvar för returpapper (The Ordinance of Producers' Responsibility for Waste Paper). SFS 1994:1205, 1994.

14. SFS1994b, Förordningen om producentansvar för förpackningar (The Ordinance of Producers' Responsibility for Packaging Materials). SFS 1994:1235, 1994.

15. Förpackning- och tidningsinsamling (FTI). About FTI. Available online: http://www.ftiab.se/forforetag/ inenglish.4.53781b2513d681fd9d51ff8.html (accessed on 24 June 2013), (in English).

16. SvenskGlasÅtervinning. Glass recycling. Available online: http://www.glasatervinning.se/ index.php/om-sga (accessed on 24 June 2013), (in Swedish).

17. Förpackning- och tidningsinsamling (FTI). Statistic. Available online: http://www.ftiab.se/180.html (accessed on 24 June 2013), (in Swedish).

18. Borås Energi och Miljö. Sorteringsguide (in Norwegian); Borås Energi och Miljö: Borås, Sweden, 2008.

19. SAKAB. Treatment the hazardous waste. Available online: http://www.sakab.se/en/ treatment-hazardous-waste (accessed on 24 June 2013).

20. Morrissey, A.J.; Browne, J. Waste management models and their application to sustainable waste management. Waste Manage. 2004, 24, 297-308.

21. Tsiliyannis, C.A. Report: Comparison of environmental impacts from solid waste treatment and disposal facilities. Waste Manage. Res. 1999, 17, 231-241.

22. Rabl, A.; Spadaro, J.V.; Zoughaib, A. Environmental impacts and costs of solid waste: A comparison of landfill and incineration. Waste Manage. Res. 2008, 26, 147-162.

23. Emery, A.; Davies, A.; Griffiths, A.; Williams, K. Environmental and economic modelling: A case study of municipal solid waste management scenarios in Wales. Resour. Conserv. Recy. 2007, 49, 244-263.

24. Dahlén, L. Household Waste Collection: Factors and Variations. Ph.D. Thesis, Luleå University of Technology, Luleå, Sweden, 2008.

25. Dahlén, L.; Vukicevic, S.; Meijer, J.-E.; Lagerkvist, A. Comparison of different collection systems for sorted household waste in Sweden. Waste Manage. 2007, 27, 1298-1305.

26. Larsen, A.W.; Merrild, H.; Møller, J.; Christensen, T.H. Waste collection systems for recyclables: An environmental and economic assessment for the municipality of Aarhus (Denmark). Waste Manage. 2010, 30, 744-754. 
27. Swedish Statistisc. Socio-Economic Statistics; SCB: Stockholm, Sweden, 2012.

28. Berg, P.E. Source Sorting. Theory, Method and Implementation/Källsortering. Teori, Metod och Implementering/. Doctoral Thesis (in Swedish); Institutionen för Vattenförsörjnings-och Avloppsteknik, Chalmers Tekniska Högskola: Göteborg, Sweden, 1993.

29. Swedish Waste Management. Manual for Pick Analysis of Houshold Waste/Manual för Plockanalys av Hushållsavfall (in Swedish); RVF Utveckling 2005:19; Avfall Sverige: Malmö, Sweden, 2005.

30. Hans Skoglund. Borås Energi och Miljö, Borås, Sweden. Personal communication, 2 March 2012.

31. Göran Nilsson. Pressretur, Stockholm, Sweden. Personal communication, 4 April 2013.

32. Pressretur. About us. Available online: http://www.pressretur.se/omoss.4.328c401048bb 6f3da80001245.html (accessed on 24 June 2013).

33. REPA. Packaging fee. Available online: http://www.repa.se/avgifterregler/avgifter.4.3bd4d bee12c726a177a8000215.html (accessed on 24 June 2013).

34. Per Johansson. SvenskGlasÅtervinning, Hammar, Sweden. Personla communication, 4 April 2013.

(C) 2013 by the authors; licensee MDPI, Basel, Switzerland. This article is an open access article distributed under the terms and conditions of the Creative Commons Attribution license (http://creativecommons.org/licenses/by/3.0/). 